ARTICLE

DOI: $10.1038 /$ s41467-018-07312-9

\title{
Normal faulting and viscous buckling in the Tibetan Plateau induced by a weak lower crust
}

\author{
Sarah H. Bischoff(D) ${ }^{1} \&$ Lucy M. Flesch (i) ${ }^{1}$
}

Flow of weak lower crust has been invoked to reconcile observed topographic gradients, uniform elevations, slow seismic velocity, and high conductivity measured in the Tibetan Plateau, with viscosity estimates of $10^{16}-10^{21} \mathrm{~Pa} \cdot \mathrm{s}$. Here we investigate the dynamic response resulting from a range of lower crust viscosities in a 3-D lithospheric-scale geodynamic simulation of the India-Eurasia collision zone to determine bounds of physically viable lower crustal strengths. We show that thickening of the plateau is accommodated through viscous buckling of the upper crust in response to lower crustal flow for a lower crustal viscosity on the order of $10^{20} \mathrm{~Pa}$.s. This generates two east-west trending bands of surface subsidence and dilatation consistent with observed normal faulting and estimates of vertical velocity. These results suggest viscous buckling of the upper crust, induced by lower crustal flow from gravitational pressure gradients due to high topography, is responsible for the observed extension in Tibet.

\footnotetext{
${ }^{1}$ Department of Earth, Atmospheric \& Planetary Sciences, Purdue University, West Lafayette, IN 47907, USA. Correspondence and requests for materials should be addressed to L.M.F. (email: Imflesch@purdue.edu)
} 
$\mathrm{T}$ he Tibetan Plateau, with an average elevation of $5 \mathrm{~km}$ over a lateral scale of $1000 \mathrm{~s}$ of $\mathrm{km}$, exhibits a complex pattern of deformation. It is well established the largescale north-south compression and lithospheric thickening results from collision of the continental Indian and Eurasian plates; however, questions remain as to the mechanism responsible for generating the observed east-west extension, normal faulting, and subsidence extending parallel to the margin. Proposed hypotheses include gravitational collapse of high topography, convective removal of a thickened lithospheric mantle, reduction in rate of Indian convergence, spreading of weak Eurasian crust over subducted Indian slab, interaction between Eurasian crust and discontinuities in subducted Indian lower crust, and geometry of Indian collision ${ }^{1-8}$. The dynamics of the Tibetan Plateau have been widely and successfully approximated by thin viscous sheet (TVS) models, which assume negligible horizontal shear and treat the lithosphere as a homogeneous sheet with only lateral strength variations $^{1,2}$ (and references therein). However, observations of high conductivity ${ }^{9}$, slow seismic velocity ${ }^{10}$, and radial anisotropy ${ }^{11}$ have been interpreted as a pervasive weakness in the Tibetan lower crust that could indicate deviation from the TVS assumptions ${ }^{12}$. In addition, flow of weak lower crust has been posited to reconcile crustal thickening of the eastern plateau in the absence of appreciable upper crustal shortening, variable topographic gradients from high-to-low elevations ${ }^{13}$, and low plateau surface relief ${ }^{14}$ with viscosity estimates ranging from $10^{16}$ to $10^{21} \mathrm{~Pa} \cdot \mathrm{s}^{13,15,16}$. Laboratory-derived lithospheric strength envelopes ${ }^{17}$ predict low strength in continental lower crust, presumably augmented by anomalously high crustal temperatures in Tibet ${ }^{18}$ and perhaps associated with enhanced radioactive heat production in the doubly-thick crust ${ }^{19}$.

Previous geodynamic simulations of lower crustal deformation in Tibet have primarily focused on estimating the viscosity required to generate observed topographic relief ${ }^{15}$ and gradients $s^{13}$ along 2D profiles, or full 3-D time-dependent thermomechanical derivation of viscosity with assumed flow laws and temperature gradients ${ }^{20-22}$ to assess the effects of crustal thickness and viscosity variations and required driving forces in generating both topographic features and continental subduction ${ }^{23-25}$. Since $2 \mathrm{D}$ simulations neglect flow in and out of the third dimension and thermomechanical simulations derive strength distributions rather than test a given hypothetical distribution determined from geophysical data, neither approach addresses the lithospheric wide influence of an assumed lower crustal strength.

In this work we perform 3-D lithospheric-scale simulations of the India-Eurasia (IN-EU) collision zone, varying lower crustal strength for published viscosity estimates ranging from $10^{19}$ to $10^{21} \mathrm{~Pa} \cdot \mathrm{s}$ to explicitly determine the lithospheric surface response and assess the level of lower crustal flow, for an assumed layeraveraged lower crustal strength. Geodynamic simulations are governed by incompressible steady state Stokes-flow within a $100 \mathrm{~km}$ thick spherical cap simulation driven by edge velocity conditions and gravity acting on 3-D varying material properties. We use a viscous rheology to estimate the accumulation of stress and deformation over multiple seismic cycles, and approximates the depth-varying material property of the upper crust. We divide the model geometry between Indian plate indenter and Eurasian upper crust, lower crust, and lithospheric mantle (see Fig. 1a, b and Methods), assuming lateral bounds of weak lower a

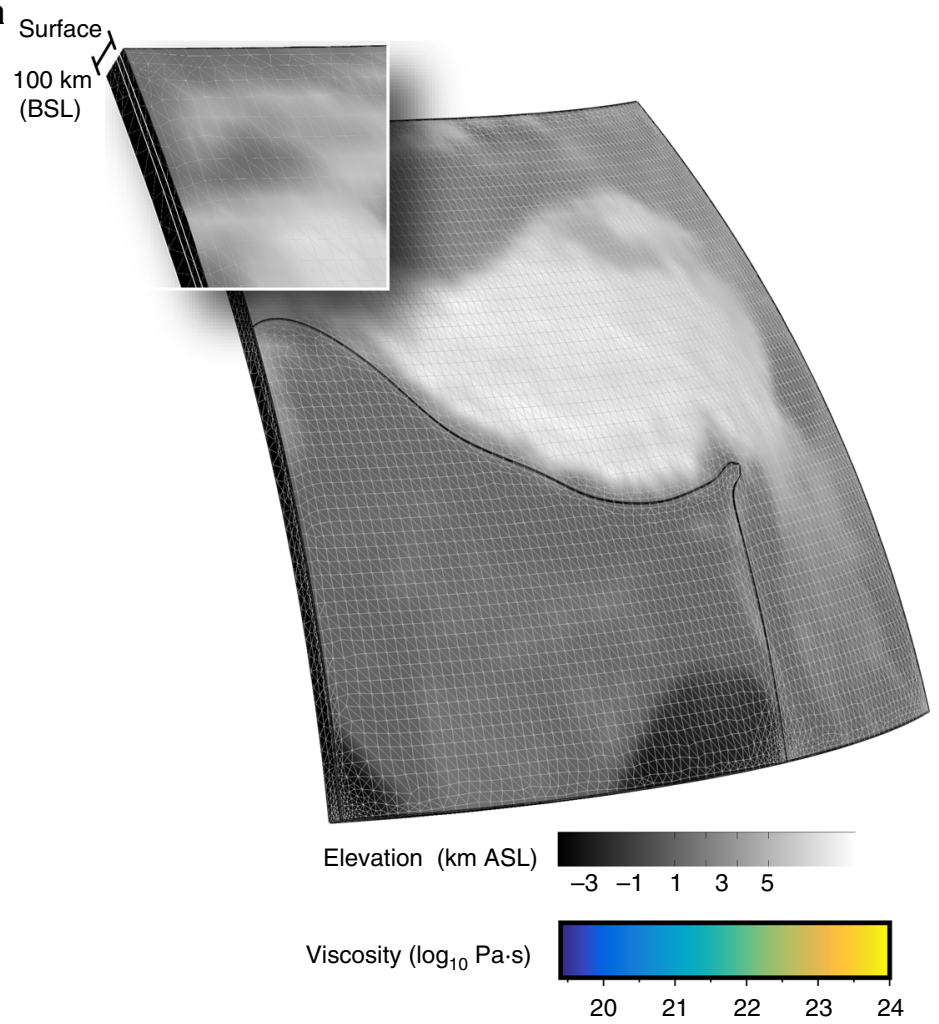

b

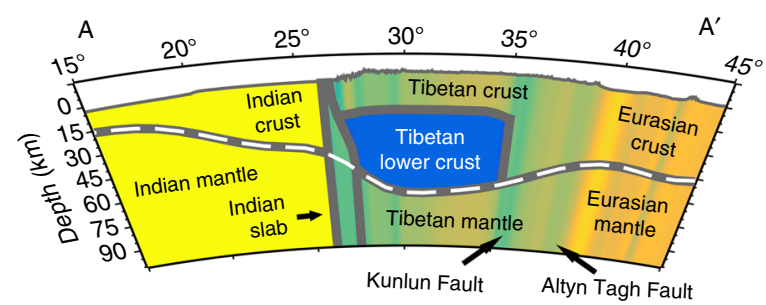

C

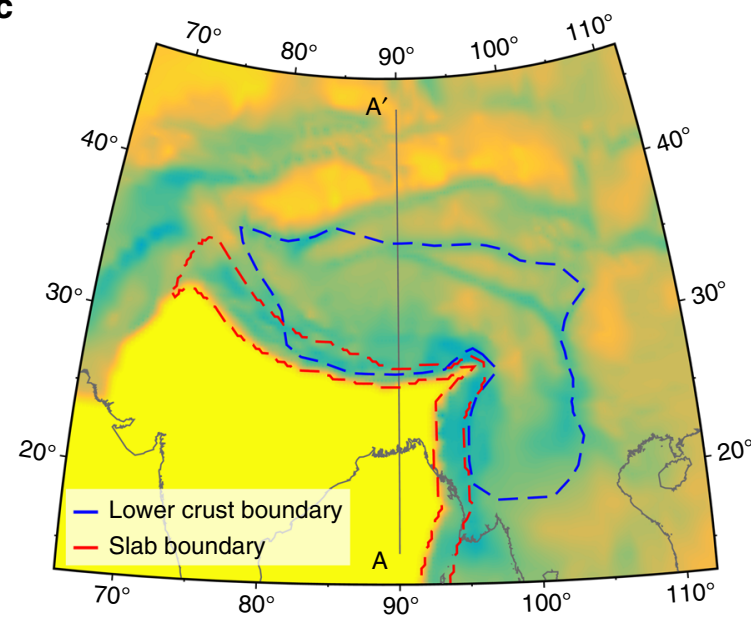

Fig. 1 Schematic of model geometry and viscosity distribution. a Geometry with color scale representing elevation above sea level, gray lines delineating mesh elements, and black line showing Indian/Asian domain boundary. Inset shows enlarged geometry corner, with white lines showing Asian upper/lower crust and mantle domains. b Cross-section of model at $90^{\circ} \mathrm{E}$ with color scale representing viscosity variation, gray lines delineating regions with vertically coherent viscosity, and dashed white line showing Moho. c Map-view of model showing vertically-averaged lithospheric effective viscosity and dashed blue/red lines outlining surface projections of weak lower crust/slab regions. A-A' line locates cross-section in $\mathbf{b}$ 
crust in Tibet correspond to zones of slow seismic velocity ${ }^{10,26,27}$, high conductivity ${ }^{9,28}$, and aseismicity ${ }^{27,29}$ (Fig. 1c). Becaus several studies have demonstrated the importance of lateral strength heterogeneity and pre-existing lithospheric structure in generating geophysical features that correlate with the Tibetan Plateau $1,20,23,24,30$, we use the lateral strength heterogeneity based on the updated vertically-averaged lithospheric effective viscosity estimates of Flesch et al. ${ }^{1,30}$ (Fig. 1). This geophysical observation based laterally varying effective viscosity field has a strong Indian plate, Tarim Basin, Gobi platform, and Sichuan Basin. Overall, Tibet, the Pamir, and Tien Shan are two orders of magnitude weaker than the stronger blocks. Additionally, even weaker regions are estimated in areas of well-developed faults (southern Tibet, Altyn-Tagh Fault, Kunlun Fault, Chaman Fault, Xianshuihe Fault, Jiali Fault, Saigan Fault, and the Himalayan Front). In order to determine a 3-D viscosity structure we require that where a weaker lower crust is present (dashed blue lines Fig. 1c) the reductions in the lower crustal layer viscosity imply increased upper crust/lithospheric mantle strength given a one-to-one ratio between upper crust and mantle strength ${ }^{31}$ including a high viscosity zone beneath Tibet representing the subducted Indian slab ${ }^{32}$ (dashed red lines Fig. 1c). Here we focus on isolating the surface deformation response to vertical strength heterogeneity produced by the inclusion of a weak lower crust, vary lower crustal viscosities and utilize a constant 3-D density distribution estimated from CRUST $1.0^{33}$ for all model simulations. We find Poiseuille flow of a weak lower crust, on the order of $10^{20} \mathrm{~Pa} \cdot \mathrm{s}$, induced by gradients of gravitational potential energy resulting from high topography causes the strong upper crust to viscously buckle generating bands of east-west uplift, surface subsidence and dilatation that drives normal faulting in southern and central Tibet.

\section{Results}

Impact of lower crustal strength on mechanism of deformation. All three simulations for lower crustal viscosities ranging from $10^{19}$ to $10^{21} \mathrm{~Pa} \cdot \mathrm{s}$, as well as a simulation with uniform crustal strength (TVS), produce similar horizontal surface velocities (Fig. 2a), indicating that the strength variations at depth are indistinguishable when using horizontal surface motions alone $\mathrm{e}^{30}$. However, the predicted surface vertical velocity for each of the solutions demonstrates a strong dependence on lower crustal strength (Fig. 3). The weak lower crust, squeezed between the converging Indian plate to the south and strong lithospheric blocks to the north and east ${ }^{20}$, Tarim and Sichuan basins respectively, deforms under ductile simple shear in simulations when the lower crustal viscosity is $10^{21} \mathrm{~Pa} \cdot \mathrm{s}$ or larger, producing pronounced uplift along the Himalayan front and distributed uplift across Tibet (Fig. 3e, f). In contrast, for lower crustal viscosities of $10^{20} \mathrm{~Pa} \cdot \mathrm{s}$ and below, Poiseuille flow begins to develop wherever lateral crustal thickness variations generate the requisite gravitational pressure gradients due to the thick crust and high topography (Fig. $3 \mathrm{k}, 1$ ). Additionally in simulations developing Poiseuille flow, the large strength contrast between upper and lower crust prevents deformation in the stronger upper crust from occurring at the same rate as the underlying fastflowing, weak lower crust, causing the upper crust to viscously buckle $^{34}$ (and references therein) to maintain plateau continuity. The viscous buckling generates alternating east-west bands of uplift and subsidence at a wavelength of $\sim 320 \mathrm{~km}$ over the portion of the plateau underlain by weak lower crust (Fig. 3g, h). Upper-to-lower crust strength contrasts can exceed two orders of magnitude in these simulations, locally decoupling motion of the upper and lower crust $^{12}$
Comparison between simulated and observed crustal deviatoric stresses indicate a weak lower crustal viscosity on the order of $10^{20} \mathrm{~Pa} \cdot \mathrm{s}$ is able to reproduce observations, in agreement with other studies ${ }^{15,21,35}$, and produces the best fit statically to observed Global Positioning System (GPS) data for each case (Table 1). Since the division of lithospheric-averaged viscosity into layers of distinct strength is inherently a non-unique process, we cannot preclude the case of weaker lower crustal viscosities provided the layer of weakness is thinner than that we have modeled here ${ }^{16}$. However, assuming our inferred model geometry is appropriate for IN-EU geodynamics, only a weak lower crust viscosity of $10^{20} \mathrm{~Pa}$.s successfully reproduces the observed pattern of compression at the Himalayas, east-west tension in southern and northern Tibet, north-south tension in eastern Tibet, and east-west tension in Yunnan (Fig. 2c). Simulations with weaker lower crustal strength produce crustal tensional deviatoric stresses at significant angles to observed normal faulting.

In order to be confident the observed viscous buckling is not an artifact of the estimated geophysical observationally based lateral strength distribution (Fig. 1), we perform two additional sets of numerical block simulations where we first assume Indian lithosphere is $10^{24} \mathrm{~Pa} \cdot \mathrm{s}$, the Asian lithosphere is $10^{23} \mathrm{~Pa} \cdot \mathrm{s}$ and weak lower crust of $10^{20} \mathrm{~Pa} \cdot \mathrm{s}$. In the second simulation, we assume the Indian lithosphere is $10^{24} \mathrm{~Pa} \cdot \mathrm{s}$, the Asian lithosphere is $10^{23} \mathrm{~Pa} \cdot \mathrm{s}$, the Tibetan lithosphere is $10^{22} \mathrm{~Pa} \cdot \mathrm{s}$ and weak lower crust of $10^{20} \mathrm{~Pa} \cdot \mathrm{s}$. We find that viscous buckling occurs regardless of lateral variations in effective viscosity (Supplementary Figure $1 \mathrm{a}, \mathrm{b}$ ), it is only dependent on the location and extent of the weaker lower crust and the strength contrast between the upper and lower crust such that Poiseuille flow develops. However, the predicated surface horizontal velocity field and crustal deviatoric stress fields for these two simulations produce a degraded fit with observations in comparison to simulations utilizing a geophysical observationally based estimated lateral strength distribution (Table 1). These block simulations yield further support that weakening the lower crust sufficiently for the development of Poiseuille flow will lead to rates of deformation in the lower crust that are too high for the upper crust to maintain and thus requires the upper crust to viscously buckle in order to maintain plateau continuity. The extent of buckling in the upper crust is contained to regions that overlay a weaker lower crust.

Due to the fact that seismic and MT studies have argued that the weak lower crustal layer in Tibet extends to $50 \mathrm{~km}$ depth ${ }^{9,10}$, we perform one final simulation to investigate the effect of thickness of the weak lower crustal layer on viscous buckling. This final simulation is identical to that presented in Fig. $3 \mathrm{c}, \mathrm{g}, \mathrm{k}$ with the exception that the weak lower crustal layer is uniform everywhere extending from $20 \mathrm{~km}$ to $50 \mathrm{~m}$ depth. We find that the presence of a weak lower crustal layer that does not extend to the Moho will still develop Poiseuille flow inducing viscous buckling in the upper crust (Supplementary Figure 1c) and produces a fit to the observed GPS data on the order of the case with a thicker weak lower crust with a viscosity of $10^{20} \mathrm{~Pa} \cdot \mathrm{s}$ (Table 1).

Vertical motion as a proxy for dynamics of lower crust. As noted by Bendick and Flesch ${ }^{34}$, we find that horizontal surface velocities are nearly indistinguishable within uncertainty across the entire region of simulated vertical strength distributions tested here (Fig. 2a). However, we find significant variance between vertical surface motions produced in simulations with different lower crustal strengths (Fig. 3e-h), hence observations of vertical motion in Tibet provide the additional constraints in order to distinguish between physically viable numerical simulations. Paleoelevation estimates derived from fossil flora enthalpy ${ }^{36}$ and isotope-elevation 


\footnotetext{
$\rightarrow$ GPS modeled velocity

$\rightarrow$ Model velocity solution, no weak lower crust

$\rightarrow$ Model velocity solution, lower crust $10^{21} \mathrm{~Pa} \cdot \mathrm{S}$

$\rightarrow$ Model velocity solution, lower crust $10^{20} \mathrm{~Pa} \cdot \mathrm{S}$

$\rightarrow$ Model velocity solution, lower crust $10^{19} \mathrm{~Pa} \cdot \mathrm{s}$
}

a

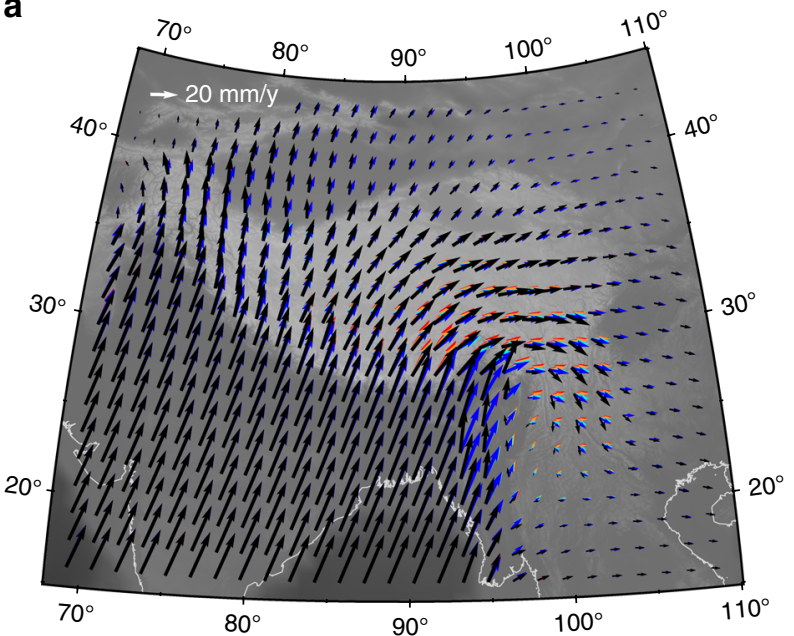

c

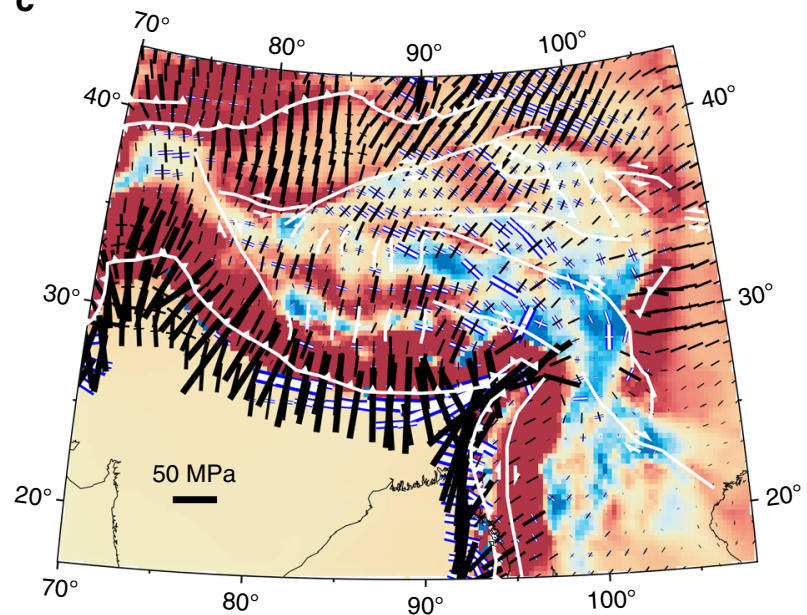

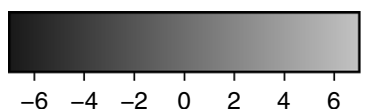

Elevation ( $\mathrm{km}$ above sea level)

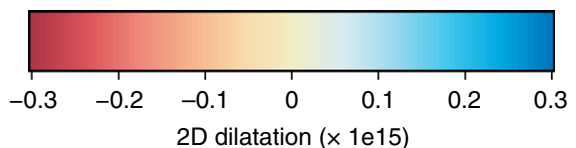

b

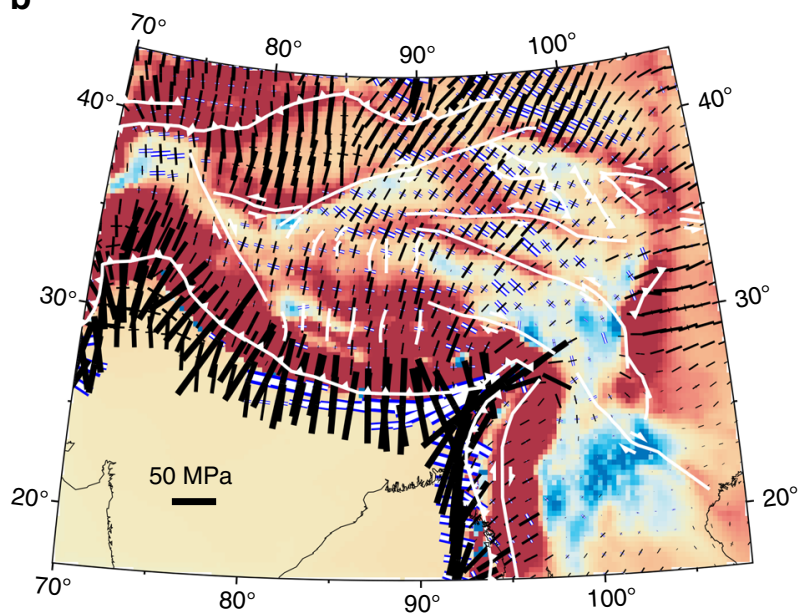

d

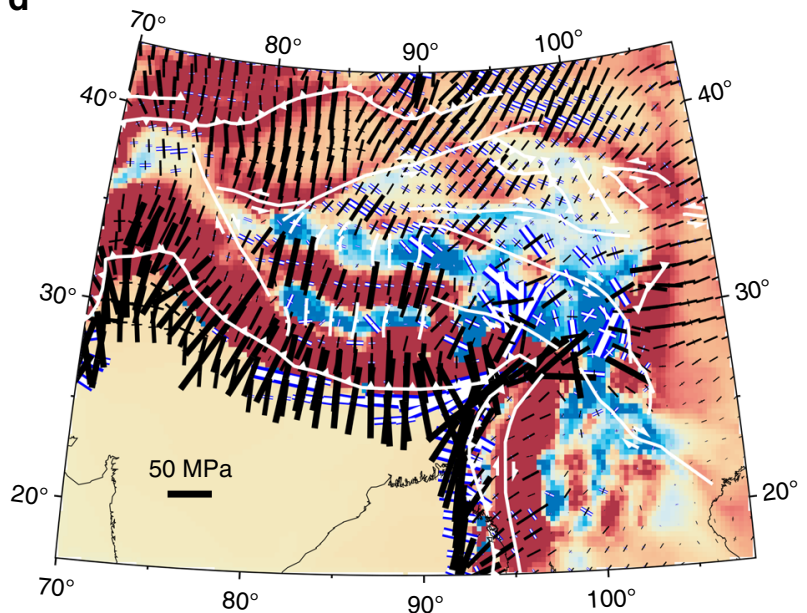

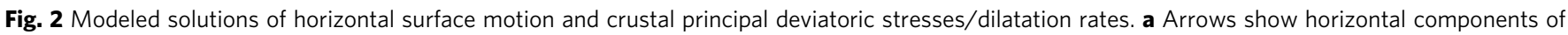
surface deformation modeled from GPS observations (black), and test cases with lower crust characterized by no weak lower crust (red), and weak lower

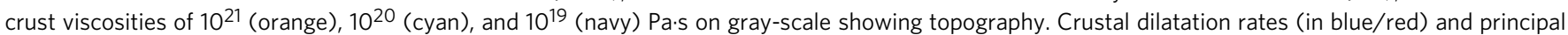

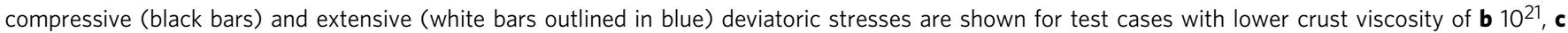
$10^{20}$, and $\mathbf{d} 10^{19} \mathrm{~Pa}$.s. White lines mark major faults

relationships ${ }^{37-44}$ across the IN-EU collision zone reveal a spatially varying pattern of uplift and subsidence since the Miocene (Fig. 4). Additionally, Liang et al. ${ }^{45}$ approximate present-day vertical tectonic motion of Tibet by relating vertical GPS observations across Tibet to measurements from three continuous stations located on stable blocks to the north. While paleoelevation estimates provide no constraints on uplift rate and age estimates of individual sites vary widely from 45 to $5 \mathrm{Ma}$, both the paleoaltimetry and geodetic results reveal an alternating pattern of margin parallel uplift and subsidence across southern Tibet roughly coincident with the surface uplift and subsidence patterns produced by simulations with weak lower crust of $10^{20} \mathrm{~Pa} \cdot \mathrm{s}$ and below (Fig. $3 \mathrm{~g}, \mathrm{~h}$ ). However, simulations with lower crustal viscosity $10^{19} \mathrm{~Pa} \cdot s$ and below produce high rates of lower crustal mass flux (in some places $>40 \mathrm{~mm} /$ $\mathrm{yr}$ ), resulting in unphysical rates of uplift and subsidence (Figs $2 \mathrm{~d}$ and $3 \mathrm{~h}, \mathrm{l})$. Thus, our simulations bound lower crustal viscosity as $<10^{21} \mathrm{~Pa} \cdot \mathrm{s}$ and $>10^{19} \mathrm{~Pa}$.s. Additionally, these simulations yield high rates of uplift at the eastern and western syntaxes, in good agreement with observations of very high rates of recent rock uplift ${ }^{46}$.

Spatial correlation in gravity lows and simulated buckling. Two parallel east-west trending bands of gravity lows evident from terrestrial and satellite gravity observations at wavelengths of $150-500 \mathrm{~km}$ have been variably interpreted as folding of the Moho in response to tectonic compression or underthrusting of the Indian lower crust ${ }^{47-49}$. The locations of the gravity lows are spatially well correlated with the simulated bands of surface subsidence, corresponding to the buckling of the simulated upper crust (Fig. 3g, h). Thus, gravity observations may also be sensitive to the proposed buckling in the upper crust. We posit, if the crust and the mantle are of the same strength as they are in the simulations presented here, when Poiseuille flow of the lower crust develops the lithospheric mantle would likewise buckle for plateau continuity, and because the spatial scale is controlled by 
a

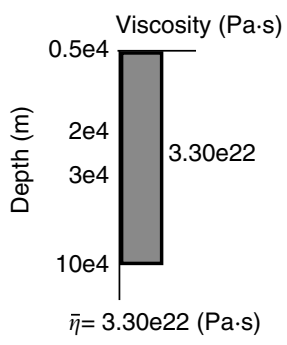

b

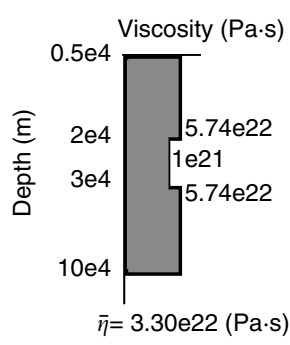

C

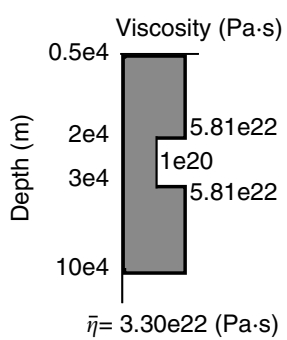

d

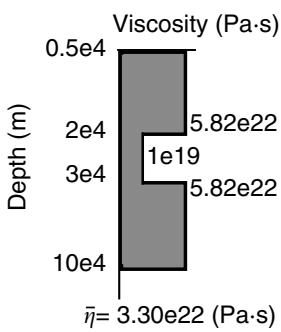

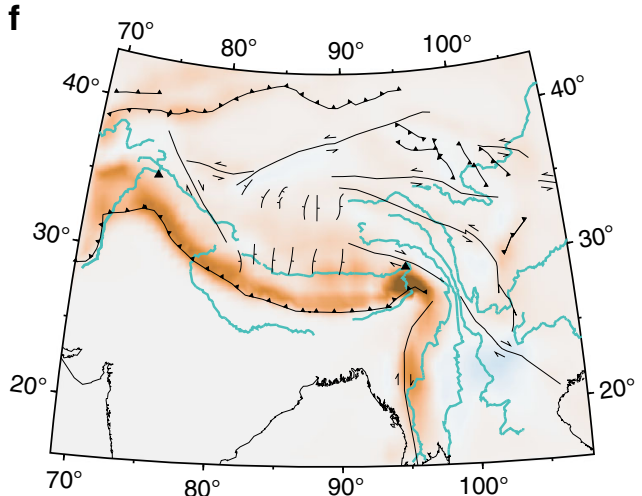

g

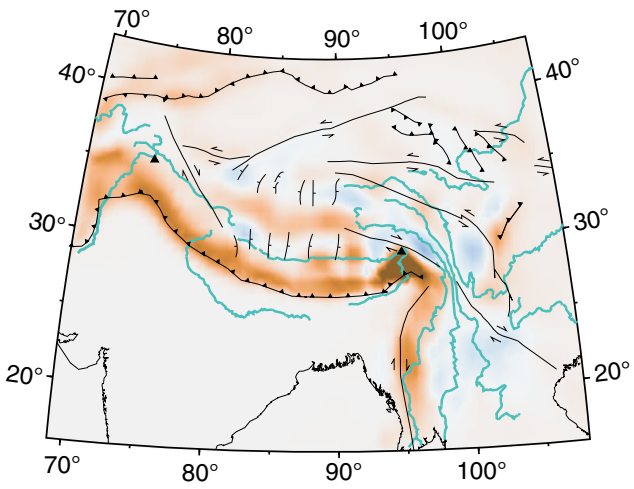

e

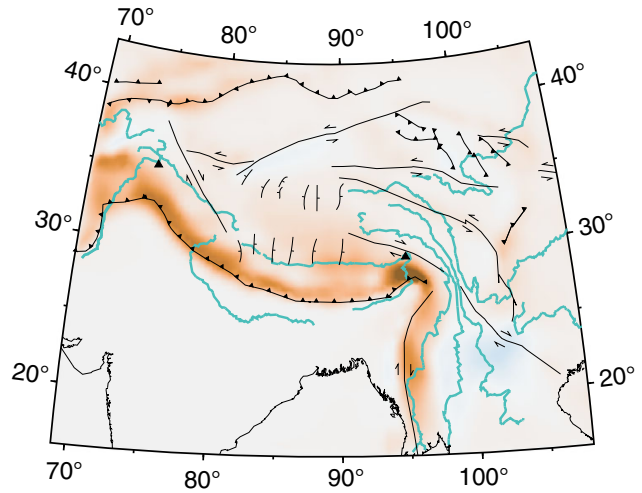

$f$

h

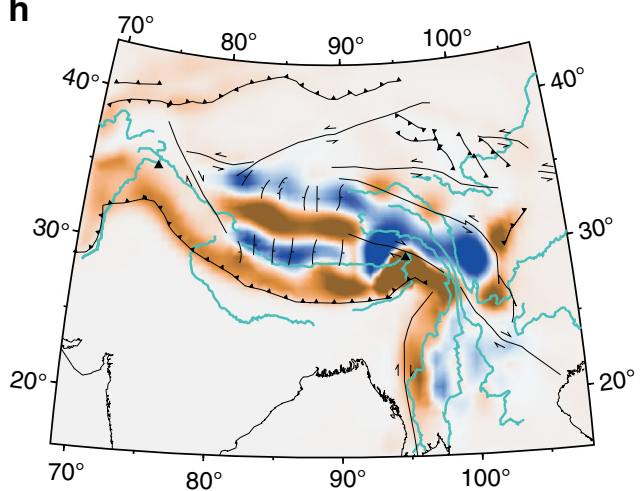

Vertical velocity

$(\mathrm{mm} / \mathrm{y})$

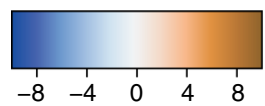

i

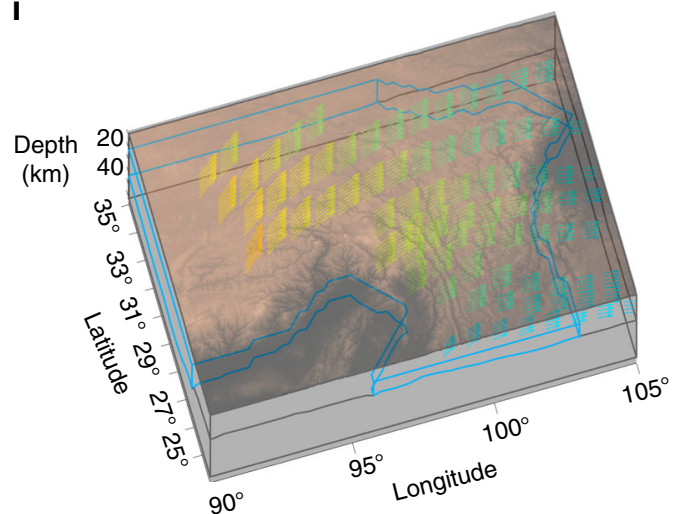

j

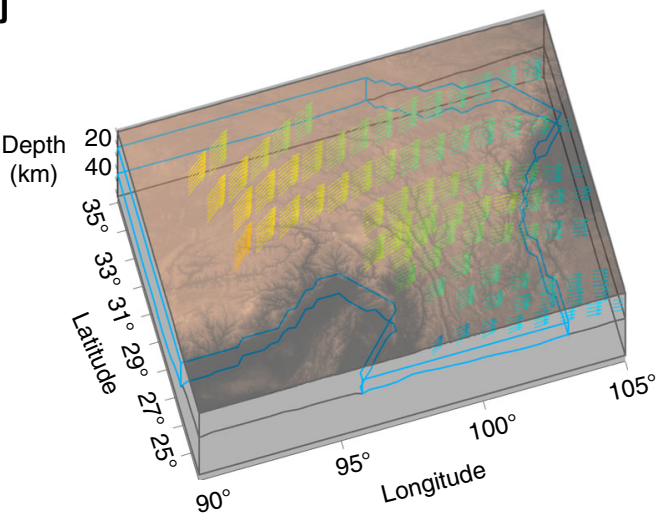

k

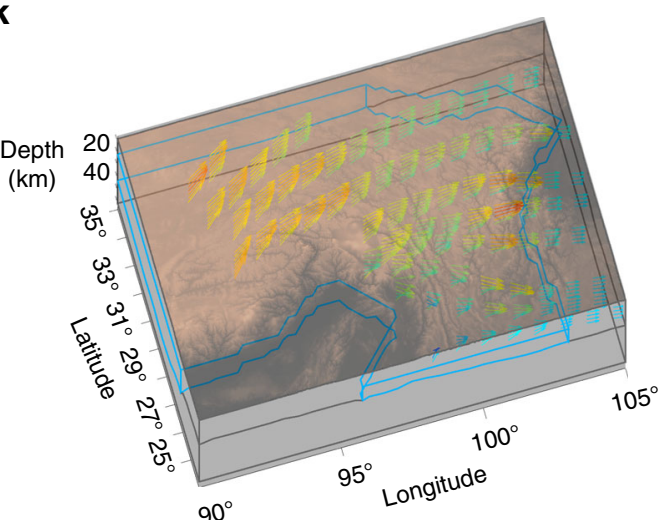

I

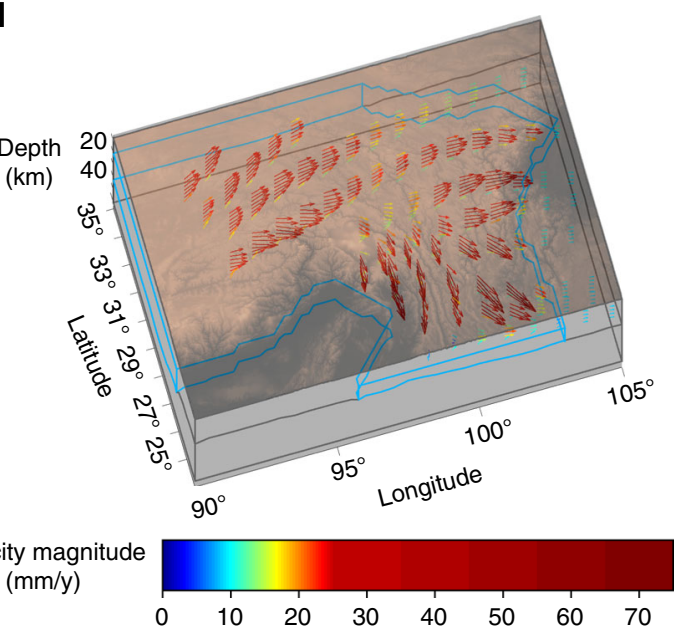


Fig. 3 Modeled solutions of vertical surface motion and lower crust velocity. Viscosity-depth profiles at $30^{\circ} \mathrm{N}, 99^{\circ} \mathrm{E}$ for test cases with lower crust characterized by a no weak lower crust, b $10^{21}$, c $10^{20}$, and d $10^{19} \mathrm{~Pa} \cdot \mathrm{s}$. e-h Model solutions with color scale representing surface vertical velocity, teal lines/black symbols marking major rivers/faults, and black triangles denoting locations of Nanga Parbat and Namche Barwa peaks. i-I Model velocity solutions in weak lower crust of Southeast Tibet, with arrow color representing magnitude, blue/gray lines outlining weak lower crust/other domains, and semi-transparent copper color scale showing topography

\begin{tabular}{|c|c|c|}
\hline Model & RMS $_{\text {misfit }}$ & WRMS $_{\text {misfit }}$ \\
\hline No weak lower crust & 6.43 & 4.78 \\
\hline $10^{21} \mathrm{~Pa} \cdot \mathrm{s}$ lower crust & 6.07 & 4.51 \\
\hline $10^{20} \mathrm{~Pa} \cdot \mathrm{s}$ lower crust & 5.19 & 3.86 \\
\hline $10^{19} \mathrm{~Pa} \cdot \mathrm{s}$ lower crust & 4.80 & 3.57 \\
\hline Case 1-block (three viscosities) & 7.42 & 4.62 \\
\hline Case 2-block (four viscosities) & 6.82 & 4.25 \\
\hline Thinner weak lower crust & 5.00 & 3.09 \\
\hline
\end{tabular}

the presence of weak lower crust one would expect them to correlate.

Origins of normal faulting in southern and central Tibet. We observe a correspondence between the simulated bands of subsidence, deviatoric stresses and patterns of dilatation for a weak lower crust on the order of $10^{20} \mathrm{~Pa}$.s with available paleoelevation and geodetic observations of vertical motion and normal faulting in southern Tibet. In part owing to poor fieldwork conditions ${ }^{45}$, no paleoelevation or vertical geodetic estimates have been produced for central Tibet where simulations of viscous buckling predict a second band of subsidence centered in western Qiangtang. However, we note the correlation of observed normal faulting in southern and central Tibet ${ }^{5}$ with the pattern of subsidence, crustal thinning (Fig. 3g) and dilatation (Fig. 2c) predicted by simulations with viscous buckling. Based on these correlations, we propose that normal faulting, extension and subsidence in southern and central Tibet is a result of viscous buckling of the Tibetan upper crust in response to faster rates of deformation and flow of the weak lower crust associated with gravitational collapse. Early crustal thickening and uplift ${ }^{50}$ of Tibet led to radioactive heating and weakening of the lower crust $^{19}$. Growth of topography and weakening of the lower crust eventually led to the development of gravitational-induced pressure gradients and high rates of Poiseuille flow of the weak lower crust, inducing viscous buckling in the stronger upper crust and initiating faulting in the late Miocene that continues to presentday $^{3}$.

Normal faulting in Tibet has been attributed to convective removal of the Tibetan mantle ${ }^{2}$, gravitational collapse of high topography ${ }^{1}$, geometry of the Indian collision ${ }^{8}$, subduction of Indian basement ridges $^{7}$, a reduction in rate of Indian convergence $^{4}$, presence of a weak lower crust ${ }^{25}$, or spreading of weak Eurasian crust over subducted Indian slab ${ }^{3}$. Fast seismic velocity anomalies interpreted as Indian and Tibetan lithosphere $^{51}$ suggests removal may not have been pronounced or plateau-wide, and that a change in collision boundary condition was not widespread. Similarly, paleoelevation evidence is not conclusive on when the Tibetan Plateau reached its present-day elevation, with many studies suggesting it may have reached high elevations well before extension began in the Miocene $e^{41}$, although some have argued for extension in southern Tibet starting in the early stage of the India/Eurasia collision ${ }^{52,53}$. Additional deformation features, including symmetrical fanning of normal fault stress trajectories about the center of the Himalayan $\operatorname{arc}^{8}$ and the difference in character between extension in southern and northern Tibet $^{3,6}$, can provide more constraints to identify the mechanism of extension. Armijo et al. ${ }^{3}$ attribute the reduction in extension rate from southern to northern Tibet in terms of the greater impact of strike-slip faulting in the northern plateau. Conversely, Styron et al. $^{6}$ suggest subduction of the Indian lower crust acts to drastically increase the rate of spreading near the toe of the underthrust slab and successfully correlate spatiotemporal evidence of the location of fastest slip along the Lunggar Rift in southern Tibet with rate of underthrusting. Thus, Styron et al. ${ }^{6}$ suggest two factors drive present-day extension: a plateau-wide event driving slow extension plateau-wide since the Miocene and augmentation of that extension in southern Tibet due to the underthrust of India.

In conclusion, we argue that normal faulting and extension in Tibet results from viscous buckling of the upper crust in response to high rates of flow of a weak lower crust and does not require a resetting of the Indian boundary condition, convective removal of the mantle, nor specifically an attainment of high elevations around the Miocene. Our simulations produce a fanning of deviatoric compressional axes normal to the Himalayan front, supporting the importance of geometry of the Indian indenter, and produce high compressional deviatoric stresses along the Himalayan front as opposed to the centralized "punch" as proposed by Kapp and Guynn ${ }^{8}$. We interpret the patterns of dilatation and subsidence in southern and central Tibet in best-fit simulations, with a lower crustal viscosity on the order of $10^{20}$ $\mathrm{Pa} \cdot \mathrm{s}$, as a response to the presence and high rates of flow of a weak lower crust that is limited and/or missing in the north $^{27-29,54,55}$ (Fig. 1c). Thus, in the north, the upper and lower crust deform at approximately the same rate, removing the need for viscous buckling of the upper crust and extension here is accommodated through strike-slip deformation of the whole lithosphere at lower rates (Fig. 2c).

It is important to note that our results are consistent with the TVS models that demonstrate gravitational collapse is responsible for the distributed extension within all of southern and central Tibet ${ }^{1}$. As the simulations move to $3-\mathrm{D}$ and incorporate vertically variable strength distribution with a weaker lower crust, gravitational collapse now drives high rates of deformation and flow of the weaker lower crust that in turn induces viscous buckling of the stronger upper crust in order to deform at the same rate as the lower crust. Viscous buckling of the upper crust results in bands of east-west subsidence and dilatation that generates observed normal faulting and thinning. In each case gravitational collapse drives the observed extension in Tibet, however, in the simulations presented here, which incorporates vertical strength contrasts, extension is no longer uniformly distributed but localized within two east-west trending zones consistent with geologic observations.

\section{Methods}

Geodynamic simulation geometry and parameterization. We implement a 3-D lithospheric, finite element model (Fig. 1a) of the IN-EU collision zone in COMSOL Multiphysics (www.comsol.com). Our spherical shell geometry encompasses major features of the IN-EU collision zone; spanning from 15 to $45^{\circ} \mathrm{N}$ and 68 to $110^{\circ} \mathrm{E}$. The model upper surface is represented by ETOPO5 Earth topography (http://www.ngdc.noaa.gov/mgg/global/relief/ETOPO5/); the model base is 

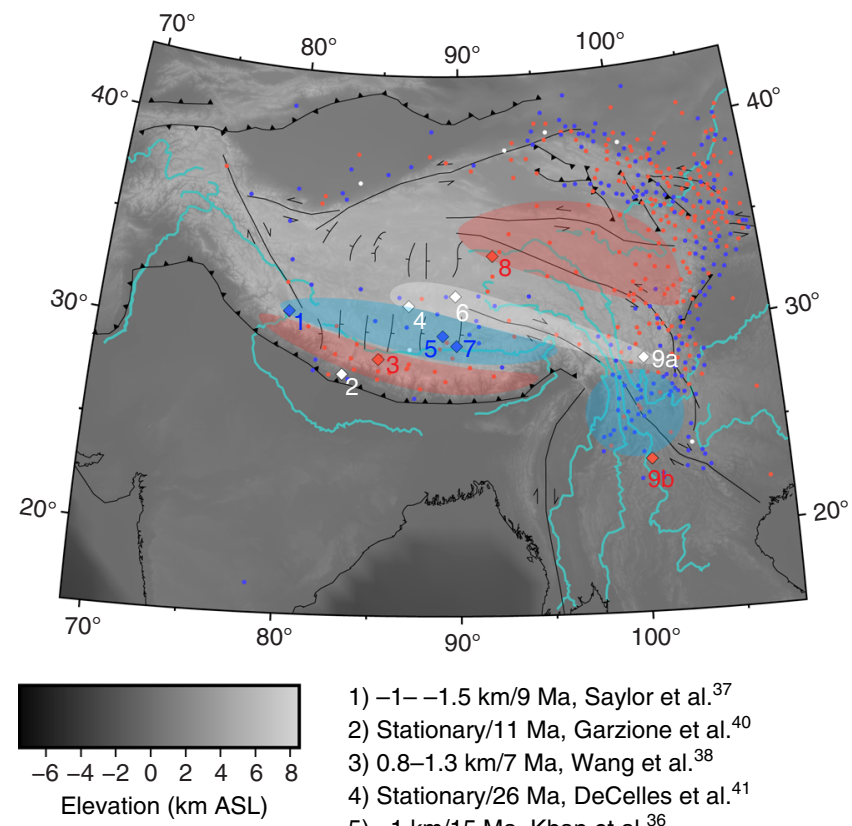

1) $-1--1.5 \mathrm{~km} / 9 \mathrm{Ma}$, Saylor et al. ${ }^{37}$

2) Stationary $/ 11 \mathrm{Ma}$, Garzione et al. ${ }^{40}$

3) $0.8-1.3 \mathrm{~km} / 7 \mathrm{Ma}$, Wang et al. ${ }^{38}$

4) Stationary/26 Ma, DeCelles et al. ${ }^{41}$

5) $-1 \mathrm{~km} / 15 \mathrm{Ma}$, Khan et al. ${ }^{36}$

- GPS measurement

- Paleoelevation study

- Positive uplift

- Negative uplift

$\square$ Stationary uplift

6) Stationary/39 Ma, Rowley \& Currie ${ }^{42}$

7) $>-1 \mathrm{~km} / 5 \mathrm{Ma}$, Currie et al. ${ }^{39}$

8) $>2.7 \mathrm{~km} / 38 \mathrm{Ma}$, Cyr et al. ${ }^{43}$

9a) Stationary/45 $\mathrm{Ma}$ \}

9b) $1 \mathrm{~km} / 5 \mathrm{Ma}\}$ Hoke et al. ${ }^{44}$

Fig. 4 Combined evidence for positive/negative surface motion determined from GPS and paleoelevation studies. Evidence for positive (red), negative (blue), or negligible uplift across IN-EU collision zone from GPS observations (dots) and paleoelevation studies (numbered diamonds). Numbers are listed with corresponding citations and associated uplift rates. Gray-scale, black symbols, and teal lines represent topography, major faults, and rivers, respectively

represented by an isoradial surface at $100 \mathrm{~km}$ below sea level (BSL). Three additional internal surfaces subdivide the geometry into four domains: India, Eurasia upper crust, Eurasia lower crust, and Eurasia mantle. We approximate the boundary between Indian and Eurasian plates via a subvertical surface (curved black line in Fig. 1a). To the north and west, the surface is constrained by projecting vertically down along the Himalayan Frontal Thrust (HFT) surface trace. To the east, we place the surface intersection of the Indian and Eurasian plates at the Burma Arc and constrain Burma slab dip via reported earthquake focal depths $s^{56}$. We divide the Eurasian plate into upper and lower crustal domains, with depth of the interface determined by where we place the lateral bounds for weak lower crust. For crustal regions possessing lower crustal zones of low-velocity or high conductivity, we place the upper/lower crust interface at $20 \mathrm{~km} \mathrm{BSL}$, agreeing with top of the zone of aseismicity ${ }^{27}$ and low-velocity zones ${ }^{10,57}$. For all other crustal regions, we arbitrarily place the upper/lower crust divide at half the crustal thickness. We combine observations of mid-to-lower crustal low-velocity zones from receiver function analyses 49,55,58-61, joint analyses of receiver functions and Rayleigh wave dispersion ${ }^{57,62,63}$, surface wave tomography ${ }^{10,64}$, shear wave tomography ${ }^{65}$, and deep seismic sounding ${ }^{54}$ with observations of mid-to-lower crustal zones of high conductivity $9,28,66$ to place the lateral bounds of weak lower crust (dashed blue line in Fig. 1c) clockwise from the HFT along the Karakorum, West Kunlun, Altyn-Tagh faults, west of the Sichuan Basin, and north of the Dien Bien Phu fault. Finally, we represent the boundary between Eurasian crust and mantle with Moho estimates of CRUST $1.0^{33}$.

We approximate steady state, instantaneous lithospheric deformation by the equations describing Stokes-flow in an incompressible, Newtonian fluid of 3-D varying viscosity:

$$
-\eta(x, y, z) \nabla^{2} \mathbf{u}(x, y, z)+\nabla \mathbf{p}(x, y, z)=\mathbf{F}(x, y, z)
$$

$$
\nabla \cdot \mathbf{u}(x, y, z)=0
$$

with dynamic viscosity of $\eta$, velocity vector $\mathbf{u}$, pressure $\mathbf{p}$, and body forces F. 3-D varying body forces are determined by location and 3-D density variation, with densities assumed from the estimates of CRUST $1.0^{33}$. Vertical averages of lithospheric effective viscosity (strength) are taken from the estimates of
Flesch et al. ${ }^{30}$ (Fig. 1c). We partition lithospheric averages between upper crust, lower crust, and mantle layers, such that the vertical integral is equal to the laterally varying lithospheric average according to the following relation:

$$
\bar{\eta}=\frac{1}{L} \int_{0}^{L} \eta(r) \mathrm{d} r
$$

where $L$ represents lithospheric thickness $(100 \mathrm{~km}+$ surface elevation $)$ and $r$ integrates over all depths within the column (Fig. 1b). Assuming the ratio of upper crustal to mantle strength at any lateral point is one-to-one, and assuming test values ranging from $10^{19}$ to $10^{21} \mathrm{~Pa} \cdot \mathrm{s}$ for lower crustal strength, we calculate 3-D varying viscosity distributions (Fig. 1b). As a last step, we introduce zones of slab strength $\left(10^{22} \mathrm{~Pa} \cdot \mathrm{s}\right)$ where body wave tomography ${ }^{32,67}$ indicates Indian and Burma slabs underthrust Tibet and Burma (dashed red line Fig. 1c). Where the zones of weak lower crust and strong slabs overlap, we suspend the base of the weak lower crust, normally the Moho, by the slab surface (e.g., Figure $1 \mathrm{~b}, \sim 27^{\circ} \mathrm{N}$ ). It is important to note because our method assumes a viscosity distribution a priori, we are unable to distinguish between power-law exponents (See Flesch et al. ${ }^{1}$ for details) and any assumed power law will produce the same instantaneous solution for an assumed viscosity distribution.

We apply boundary conditions on the model top and bottom consistent with frictionless sliding of the lithosphere over the asthenosphere and stress-free interaction between the atmosphere and Earth's surface. We account for driving forces induced by $3-\mathrm{D}$ density variations external to our model geometry by applying moving wall boundary conditions on each side wall, constrained by a continuous model velocity field determined from GPS observations and Quaternary fault slip rate data from Flesch et al. ${ }^{30}$ variable along each side wall.

We discretize the geometry volume with mesh generation tools within COMSOL Multiphysics. Our mesh resolution varies with position; small elements correspond to places where layers thin (e.g., Southeast Asia) and domain contacts (e.g., where Indian and Eurasian plates meet). The largest mesh elements correspond to those in domain centers, where their lateral dimensions average $0.5^{\circ}$, or about $39-54 \mathrm{~km}$ (depending on latitude). Mesh element shape varies, with prismatic elements used at domain boundaries transitioning to tetrahedral elements in domain interiors. We tune our mesh resolution to simultaneously correspond to our desired solution resolution and produce solutions qualitatively identical to those produced at higher resolutions. Our tuned mesh possesses 65,227 mesh elements (Fig. 1a).

Determination of Poiseuille flow. We develop a simple algorithm for identifying model-predicted Poiseuille flow in the lower crust. For every longitude/latitude included in the model space, we use 3-D linear interpolation to increase vertical resolution and calculate solution velocity magnitudes at all lower crustal depths. We apply a first-order, finite-impulse response (FIR), Savitzky-Golay filter to the vertical profile of solution velocity magnitudes through the lower crust; tuning filter length to yield smoothly varying profiles and minimize hot finger effects. We then sample filtered magnitudes at the top, middle, and base of the lower crust, calculating the sign of the difference from top-to-mid-layer and mid-layer-to-base magnitudes. If the difference switches sign from top-to-mid-layer and mid-layerto-base, and the magnitude mid-layer exceeds that at the top/base, we calculate the percent of top/base magnitude in relation to mid-layer. We diagnose Poiseuille flow if both top and base percentages are less then $95 \%$ of the mid-layer magnitude. Supplementary Figure 2 illustrates examples of lower crust velocity magnitude profiles for true and false positive cases with lower crust viscosities of $10^{20}$ and $10^{19} \mathrm{~Pa} \cdot \mathrm{s}$.

Block simulations. To validate that the source of the simulated viscous buckling in simulations with weak lower crust is not due to horizontal strength variation, we simulate two block models with simplified viscosity structure. In the first block simulation, case 1, we simulate a constant Indian lithosphere of $10^{24} \mathrm{~Pa} \cdot \mathrm{s}$, Asian lithosphere of $10^{23} \mathrm{~Pa} \cdot \mathrm{s}$, and weak Tibetan lower crust of $10^{20} \mathrm{~Pa} \cdot \mathrm{s}$. In the second block simulation, case 2, we again simulate a constant Indian lithosphere of $10^{24}$ Pa.s, Asian lithosphere of $10^{23} \mathrm{~Pa} \cdot \mathrm{s}$, and weak Tibetan lower crust of $10^{20} \mathrm{~Pa} \cdot \mathrm{s}$, but then add an additional level of strength variation with Tibetan lithosphere of $10^{22}$ Pa.s. The horizontal surface velocity solutions look similar to the simulations constrained by geophysical observation based estimates of lateral strength distribution, although with an overall poorer fit to GPS observations (Table 1). The vertical surface velocity solutions are shown in Supplementary Figure 1a, b. Viscous buckling is observed in both simulations, while case 2 yields slightly higher amplitude buckling due to the weaker Tibetan lithosphere, indicating simulated viscous buckling is not due to our assumed lateral strength variation.

Statistics. We quantify goodness of fit for model-predicted horizontal surface velocity through the root-mean-square (RMS) and weighted-root-mean-square (WRMS) statistics. For both statistics, we use the horizontal velocity GPS 
observations reported by Liang et al. ${ }^{45}$. We calculate RMS and WRMS misfit statistics as:

$$
\begin{gathered}
\mathrm{RMS}_{\text {misfit }}=\sqrt{\frac{\sum \frac{\left(V_{\mathrm{m}}-V_{\mathrm{o}}\right)^{2}}{\sigma^{2}}}{2 N}} \\
\mathrm{WRMS}_{\text {misfit }}=\sqrt{\frac{N}{N-1} \frac{\sum \frac{\left(V_{\mathrm{m}}-V_{\mathrm{o}}\right)^{2}}{\sigma^{2}}}{\sum \frac{1}{\sigma^{2}}}}
\end{gathered}
$$

respectively, where $V_{\mathrm{m}}$ represents model-predicted velocity at the GPS points, $V_{\mathrm{o}}$ are the GPS observations with associated uncertainty of $\sigma$, and $N$ is the number of GPS observations. For the set of GPS observations we use here ${ }^{45}, N=750$. Table 1 shows the RMS and WRMS misfits calculated for each model presented here.

\section{Data availability}

All data used in this manuscript are freely available within the Supplementary Information sections from references provided in the paper.

Received: 15 February 2018 Accepted: 26 October 2018

Published online: 23 November 2018

\section{References}

1. Flesch, L. M., Haines, A. J. \& Holt, W. E. Dynamics of the India-Eurasia collision zone. J. Geophys. Res. 106, 16435-16460 (2001).

2. England, P. \& Houseman, G. Extension during continental convergence, with application to the Tibetan Plateau. J. Geophys. Res. 94, 17561-17579 (1989).

3. Armijo, R., Tapponnier, P., Mercier, J. L. \& Han, T.-L. Quaternary extension in southern Tibet: field observations and tectonic implications. J. Geophys. Res. 91, 13803-13872 (1986).

4. Yin, A. Mode of Cenozoic east-west extension in Tibet suggesting a common origin of rifts in Asia during the Indo-Asian collision. J. Geophys. Res. 105, 21745-21759 (2000).

5. Yin, A. et al. Significant late Neogene east-west extension in northern Tibet. Geology 27, 787-790 (1999).

6. Styron, R., Taylor, M. \& Sundell, K. Accelerated extension of Tibet linked to the northward underthrusting of Indian crust. Nat. Geosci. 8, 131-134 (2015).

7. Godin, L. \& Harris, L. B. Tracking basement cross-strike discontinuities in the Indian crust beneath the Himalayan orogen using gravity data - relationship to upper crustal faults. Geophys. J. Int. 198, 198-215 (2014).

8. Kapp, P. \& Guynn, J. H. Indian punch rifts Tibet. Geology 32, 993-996 (2004).

9. Bai, D. et al. Crustal deformation of the eastern Tibetan plateau revealed by magnetotelluric imaging. Nat. Geosci. 3, 358-362 (2010).

10. Yang, Y. et al. A synoptic view of the distribution and connectivity of the midcrustal low velocity zone beneath Tibet. J. Geophys. Res. Solid Earth 117, 1-21 (2012).

11. Shapiro, N. M., Ritzwoller, M. H., Molnar, P. \& Levin, V. Thinning and flow of Tibetan crust constrained by seismic anisotropy. Science 305, 233-236 (2004).

12. Bendick, R. \& Flesch, L. Reconciling lithospheric deformation and lower crustal flow beneath central Tibet. Geology 35, 895-898 (2007).

13. Clark, M. K. \& Royden, L. H. Topographic ooze: building the eastern margin of Tibet by lower crustal flow. Geology 28, 703-706 (2000).

14. Zhao, W.-L. \& Morgan, W. J. Injection of Indian crust into Tibetan lower crust: a two-dimensional finite element model study. Tectonics 6, 489-504 (1987).

15. Bendick, R., McKenzie, D. \& Etienne, J. Topography associated with crustal flow in continental collisions, with application to Tibet. Geophys. J. Int. 175, 375-385 (2008).

16. Huang, M. H., Bürgmann, R. \& Freed, A. M. Probing the lithospheric rheology across the eastern margin of the Tibetan Plateau. Earth. Planet. Sci. Lett. 396, 88-96 (2014).

17. Kohlstedt, D. L., Evans, B. \& Mackwell, S. J. Strength of the lithosphere: constraints imposed by laboratory experiments. J. Geophys. Res. 100, 17587-17602 (1995).

18. Hacker, B. R. et al. Hot and dry deep crustal xenoliths from Tibet. Science 287, 2463-2466 (2000).

19. McKenzie, D. \& Priestley, K. The influence of lithospheric thickness variations on continental evolution. Lithos 102, 1-11 (2008).

20. Chen, L. \& Gerya, T. V. The role of lateral lithospheric strength heterogeneities in orogenic plateau growth: insights from 3-D thermomechanical modeling. J. Geophys. Res. B Solid Earth 121, 3118-3138 (2016).

21. Yang, Y. \& Liu, M. The Indo-Asian continental collision: a 3-D viscous model. Tectonophysics 606, 198-211 (2013).
22. Lechmann, S. M., Schmalholz, S. M., Hetényi, G., May, D. A. \& Kaus, B. J. P. Quantifying the impact of mechanical layering and underthrusting on the dynamics of the modern India-Asia collisional system with 3-D numerical models. J. Geophys. Res. Solid Earth 119, 616-644 (2014).

23. Pusok, A. E. \& Kaus, B. J. P. Development of topography in 3-D continentalcollision models. Geochem., Geophys. Geosystems 16, 1378-1400 (2015).

24. Chen, L., Capitanio, F. A., Liu, L. \& Gerya, T. V. Crustal rheology controls on the Tibetan plateau formation during India-Asia convergence. Nat. Commun. 8, 1-8 (2017).

25. Pang, Y. et al. The mechanism and dynamics of N-S rifting in southern Tibet: insight from 3-D thermomechanical modeling. J. Geophys. Res. Solid Earth 123, 859-877 (2018).

26. Chen, W.-P. \& Molnar, P. Focal depths of intracontinental and intraplate earthquakes and their implications for the thermal and mechanical properties of the lithosphere. J. Geophys. Res. 88, 4183-4214 (1983).

27. Andronicos, C. L., Velasco, A. A. \& Hurtado, J. M. Jr. Large-scale deformation in the India-Asia collision constrained by earthquakes and topography. Terra Nov. 19, 105-119 (2007).

28. Wei, W. et al. Detection of widespread fluids in the Tibetan crust by magnetotelluric studies. Science 292, 716-718 (2001).

29. Molnar, P. \& Chen, W.-P. Focal depths and fault plane solutions of earthquakes under the Tibetan Plateau. J. Geophys. Res. 88, 1180-1196 (1983).

30. Flesch, L., Bendick, R. \& Bischoff, S. Limitations on inferring 3D architecture and dynamics from surface velocities in the India-Eurasia collision zone. Geophys. Res. Lett. 45, 1379-1386 (2018).

31. Bischoff, S. 3-D Geodynamic Modeling of the India-Eurasia Collision Zone (Purdue University, 2017)

32. Liang, $\mathrm{X}$. et al. 3D imaging of subducting and fragmenting Indian continental lithosphere beneath southern and central Tibet using body-wave finitefrequency tomography. Earth. Planet. Sci. Lett. 443, 162-175 (2016).

33. Laske, G., Masters, G., Ma, Z. \& Pasyanos, M. E. CRUST1.0: an updated global model of Earth's crust. Geophys. Res. Abstr. 15, Abstract EGU2013-2658 (2013).

34. Bendick, R. \& Flesch, L. A review of heterogeneous materials and their implications for relationships between kinematics and dynamics in continents. Tectonics 32, 980-992 (2013).

35. Copley, A. \& McKenzie, D. Models of crustal flow in the India-Asia collision zone. Geophys. J. Int. 169, 683-698 (2007).

36. Khan, M. A. et al. Miocene to Pleistocene floras and climate of the Eastern Himalayan Siwaliks, and new palaeoelevation estimates for the NamlingOiyug Basin, Tibet. Glob. Planet. Change 113, 1-10 (2014).

37. Saylor, J. E. et al. The late Miocene through present paleoelevation history of southwestern Tibet. Am. J. Sci. 309, 1-42 (2009).

38. Wang, Y., Deng, T. \& Biasatti, D. Ancient diets indicate significant uplift of southern Tibet after ca. 7 Ma. Geology 34, 309-312 (2006).

39. Currie, B. S. et al. Multiproxy paleoaltimetry of the late Oligocene-Pliocene Oiyug Basin, Southern Tibet. Am. J. Sci. 316, 401-436 (2016).

40. Garzione, C. N., Quade, J., Decelles, P. G. \& English, N. B. Predicting paleoelevation of Tibet and the Himalaya from $\delta^{18} \mathrm{O}$ vs. altitude gradients in meteoric water across the Nepal Himalaya. Earth. Planet. Sci. Lett. 183, 215-229 (2000).

41. DeCelles, P. G. et al. High and dry in central Tibet during the Late Oligocene. Earth. Planet. Sci. Lett. 253, 389-401 (2007).

42. Rowley, D. B. \& Currie, B. S. Palaeo-altimetry of the late Eocene to Miocene Lunpola basin, central Tibet. Nature 439, 677-681 (2006).

43. Cyr, A. J., Currie, B. S. \& Rowley, D. B. Geochemical evaluation of Fenghuoshan Group lacustrine carbonates, north- central Tibet: iImplications for the paleoaltimetry of the Eocene Tibetan Plateau. J. Geol. 113, 517-533 (2005).

44. Hoke, G. D., Liu-Zeng, J., Hren, M. T., Wissink, G. K. \& Garzione, C. N. Stable isotopes reveal high southeast Tibetan Plateau margin since the Paleogene. Earth. Planet. Sci. Lett. 394, 270-278 (2014).

45. Liang, S. et al. Three-dimensional velocity field of present-day crustal motion of the Tibetan Plateau derived from GPS measurements. J. Geophys. Res. Solid Earth 118, 5722-5732 (2013).

46. Zeitler, P. K. et al. Erosion, Himalayan geodynamics, and the geomorphology of metamorphism. GSA Today 11, 4-9 (2001).

47. Jin, Y., McNutt, M. K. \& Zhu, Y. Evidence from gravity and topography data for folding of Tibet. Nature 371, 669-673 (1994).

48. Shin, Y. H. et al. Moho topography, ranges and folds of Tibet by analysis of global gravity models and GOCE data. Sci. Rep. 5, 1-7 (2015).

49. Xu, Q., Zhao, J., Yuan, X., Liu, H. \& Pei, S. Detailed configuration of the underthrusting Indian lithosphere beneath western Tibet revealed by receiver function images. J. Geophys. Res. Solid Earth 122, 8257-8269 (2017).

50. Wang, C. et al. Constraints on the early uplift history of the Tibetan Plateau. Proc. Natl Acad. Sci. USA 105, 4987-4992 (2008). 
51. Agius, M. R. \& Lebedev, S. Tibetan and Indian lithospheres in the upper mantle beneath Tibet: evidence from broadband surface-wave dispersion. Geochem., Geophys. Geosystems 14, 4260-4281 (2013).

52. Searle, M. P., Elliott, J. R., Phillips, R. J. \& Chung, S.-L. Crustal-lithospheric structure and continental extrusion of Tibet. J. Geol. Soc. Lond. 168, 633-672 (2011).

53. Wang, Q. et al. Eocene north-south trending dikes in central Tibet: new constraints on the timing of east-west extension with implications for early plateau uplift? Earth. Planet. Sci. Lett. 298, 205-216 (2010).

54. Zhang, Z. et al. An overview of the crustal structure of the Tibetan plateau after 35 years of deep seismic soundings. J. Asian Earth Sci. 40, 977-989 (2011).

55. Bai, L., Tian, X. \& Ritsema, J. Crustal structure beneath the Indochina peninsula from teleseismic receiver functions. Geophys. Res. Lett. 37, 1-6 (2010).

56. Ni, J. F. et al. Accretionary tectonics of Burma and the three-dimensional geometry of the Burma subduction zone. Geology 17, 68-71 (1989).

57. Liu, Q. Y. et al. Eastward expansion of the Tibetan Plateau by crustal flow and strain partitioning across faults. Nat. Geosci. 7, 361-366 (2014).

58. Sun, Y., Niu, F., Liu, H., Chen, Y. \& Liu, J. Crustal structure and deformation of the SE Tibetan plateau revealed by receiver function data. Earth. Planet. Sci. Lett. 349-350, 186-197 (2012).

59. Shen, X., Yuan, X. \& Ren, J. Anisotropic low-velocity lower crust beneath the northeastern margin of Tibetan Plateau: evidence for crustal channel flow. Geochemistry, Geophys. Geosystems 16, 4223-4236 (2015).

60. Xu, L., Rondenay, S. \& van der Hilst, R. D. Structure of the crust beneath the southeastern Tibetan Plateau from teleseismic receiver functions. Phys. Earth Planet. Inter. 165, 176-193 (2007).

61. Ozacar, A. A. \& Zandt, G. Crustal seismic anisotropy in central Tibet: implications for deformational style and flow in the crust. Geophys. Res. Lett. 31, 1-4 (2004).

62. Sun, X. et al. Crustal structure beneath SE Tibet from joint analysis of receiver functions and Rayleigh wave dispersion. Geophys. Res. Lett. 41, 1479-1484 (2014).

63. Bao, X. et al. Two crustal low-velocity channels beneath SE Tibet revealed by joint inversion of Rayleigh wave dispersion and receiver functions. Earth. Planet. Sci. Lett. 415, 16-24 (2015).

64. Yao, H., Van Der Hilst, R. D. \& Montagner, J. P. Heterogeneity and anisotropy of the lithosphere of SE Tibet from surface wave array tomography. J. Geophys. Res. Solid Earth 115, 1-24 (2010).

65. Gao, X., Su, Y., Wang, W., Pei, S. \& Guo, Z. Lower-crust S-wave velocity beneath western Yunnan Province from waveform inversion of dense seismic observations. Terra Nov. 21, 105-110 (2009).

66. Unsworth, M. J. et al. Crustal rheology of the Himalaya and Southern Tibet inferred from magnetotelluric data. Nature 438, 78-81 (2005).
67. Li, C., van der Hilst, R. D., Meltzer, A. S. \& Engdahl, E. R. Subduction of the Indian lithosphere beneath the Tibetan Plateau and Burma. Earth. Planet. Sci. Lett. 274, 157-168 (2008).

\section{Acknowledgements}

We benefited from discussion with Joel Saylor, Roland Burgmann, and Bill Holt. This work was supported by NSF EAR-0609337 to L.M.F.

\section{Author contributions}

L.M.F. conceived and supervised the project and S.H.B. constructed and ran the geodynamic simulations. L.M.F. and S.H.B. wrote the paper.

\section{Additional information}

Supplementary Information accompanies this paper at https://doi.org/10.1038/s41467 018-07312-9.

Competing interests: The authors declare no competing interests.

Reprints and permission information is available online at http://npg.nature.com/ reprintsandpermissions/

Publisher's note: Springer Nature remains neutral with regard to jurisdictional claims in published maps and institutional affiliations.

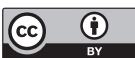

Open Access This article is licensed under a Creative Commons Attribution 4.0 International License, which permits use, sharing, adaptation, distribution and reproduction in any medium or format, as long as you give appropriate credit to the original author(s) and the source, provide a link to the Creative Commons license, and indicate if changes were made. The images or other third party material in this article are included in the article's Creative Commons license, unless indicated otherwise in a credit line to the material. If material is not included in the article's Creative Commons license and your intended use is not permitted by statutory regulation or exceeds the permitted use, you will need to obtain permission directly from the copyright holder. To view a copy of this license, visit http://creativecommons.org/ licenses/by/4.0/.

(C) The Author(s) 2018 